\title{
Systematic Review \\ A Meta-Analysis: Coronary Artery Calcium Score and COVID-19 Prognosis
}

\author{
Kevin Kyungmin Lee ${ }^{1, *(\mathbb{D}}$, Osman Rahimi ${ }^{1} \oplus$, Charlie Kyungchan Lee ${ }^{2}$, Amaan Shafi ${ }^{3}$ and Dalia Hawwass ${ }^{3}$ \\ 1 Department of Internal Medicine, University of Nevada Las Vegas, Las Vegas, NV 89102, USA; \\ osman.rahimi@unlv.edu \\ 2 Department of Mathematical Sciences, Eastern University, St. Davids, PA 19087, USA; charlie.lee@eastern.edu \\ 3 Department of Cardiology, University of Nevada Las Vegas, Las Vegas, NV 89102, USA; \\ amaan.shafi@unlv.edu (A.S.); dhawwass@gmail.com (D.H.) \\ * Correspondence: kevin.lee@unlv.edu
}

check for updates

Citation: Lee, K.K.; Rahimi, O.; Lee, C.K.; Shafi, A.; Hawwass, D. A Meta-Analysis: Coronary Artery Calcium Score and COVID-19 Prognosis. Med. Sci. 2022, 10, 5 . https://doi.org/10.3390/ medsci10010005

Academic Editor: Hiroshi Yoshida

Received: 6 January 2022

Accepted: 19 January 2022

Published: 21 January 2022

Publisher's Note: MDPI stays neutral with regard to jurisdictional claims in published maps and institutional affiliations.

Copyright: (C) 2022 by the authors. Licensee MDPI, Basel, Switzerland. This article is an open access article distributed under the terms and conditions of the Creative Commons Attribution (CC BY) license (https:// creativecommons.org/licenses/by/ $4.0 /)$.

\begin{abstract}
Background: Multiple studies have investigated the correlations of mortality, mechanical ventilation, and intensive care unit (ICU) admissions with CAC scores. This analysis overviews the prognostic capability of CAC scoring in mortality, mechanical ventilation, and ICU admission for hospitalized COVID-19 patients. Methods: Online search was conducted on PubMed, Cochrane Library, and Scopus from inception to 22 November 2021 to identify studies involving CAC scores in relation to ICU admission, mechanical ventilation, and death rates. Results: A total of eight studies were analyzed. In the absence of CAC group compared with the presence of CAC score, there was an increase in mortality in the presence of CAC (RR 2.24, 95\% CI, 1.41-3.56; $p<0.001$ ). In the low CAC group and high CAC group, high CAC group had increase in mortality (RR 2.74; 95\% CI, 1.94-3.86; $p<0.00001$ ). There was no statistical difference in outcomes of mechanical ventilation and ICU admission between any of the groups. Conclusion: This meta-analysis strictly examined the outcomes of interest in death, mechanical ventilation, and ICU admission while comparing the CAC scores in patients with COVID-19. Given these findings, CAC scoring can aid in stratifying patients, thus allowing earlier interventions in rapidly developing illnesses.
\end{abstract}

Keywords: atherosclerosis; coronary artery disease; COVID-19

\section{Introduction}

The association between coronary artery calcification (CAC) and atherosclerotic disease is well known. The CAC score was created to help guide physicians to better calculate atherosclerotic risk in non-invasive nature to stratify risk for major adverse cardiac events. Currently, Agatston scores > 100 generally delineate at least a moderate disease [1]; however, ordinal calcium scoring may also be applied to examine the extent of coronary calcifications. This analysis overviews eight studies on the prognostic capability of CAC scoring in coronavirus disease 2019 (COVID-19) hospitalizations.

Multiple studies have investigated the effects of CAC scores in hospitalized patients with COVID-19 as a potential prognostic marker. There has been some evidence of correlations in increased risk of mortality, mechanical ventilation, and intensive care unit (ICU) admissions. These studies echo that early CAC assessment can aide physicians to better triage high-risk patients. The direct and indirect effects of COVID-19 including arrhythmia, acute myocardial injury, Takotsubo syndrome, myocarditis, and delayed presentation of cardiovascular complications have been investigated [2]; however, at the time of this analysis, there has not been a systematic review and meta-analysis that assessed the prognostic capability of CAC in this patient population. 


\section{Materials and Methods}

The study was registered with the PROSPERO international database. To find relevant studies, search terms included "coronary calcium score" and "COVID-19" as well as other relevant or equivalents terms. A flowchart is outlined as follows in Figure 1 [2].

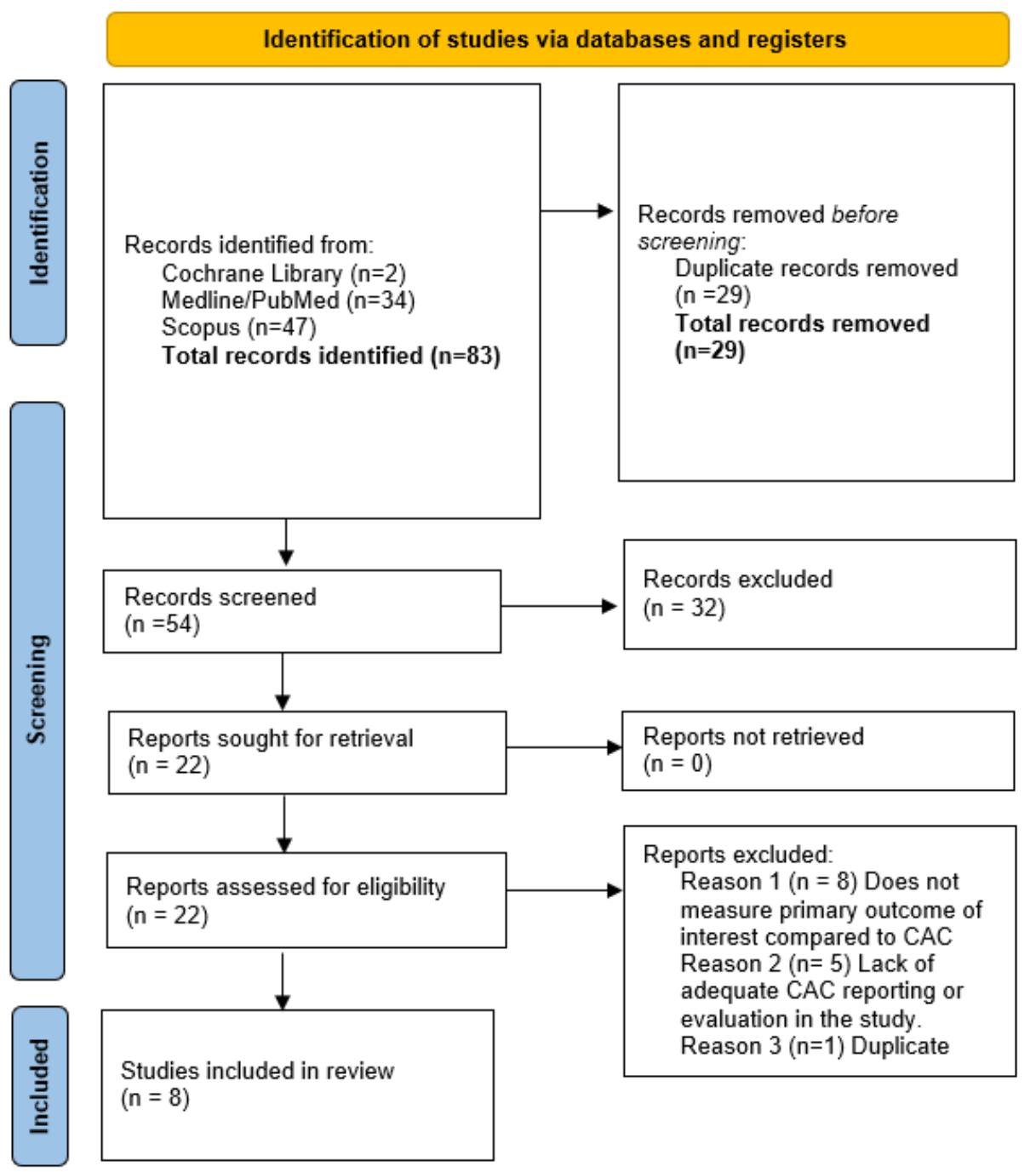

Figure 1. PRISMA flowchart.

A study was included if it (1) was an original peer-reviewed study, (2) reported CAC scoring in patients with COVID-19, and (3) investigated ICU admission, mechanical ventilation, and death rate related to individual CAC score in patients with COVID-19. There was no limitation on publication date. Language was limited to English. Review articles, case series, and case studies were excluded. An additional study that met the inclusion criteria was excluded due to an inconsistent data set when internally cross referenced.

Preferred Reporting Items for Systematic Reviews and Meta-Analyses guidelines were applied to data selection. Two authors (K.L. and O.R.) independently assessed the eligibility of each article retrieved with blinding on Rayyan platform [3]. Disagreements were arbitrated by an independent third reviewer.

\subsection{Data Extraction}

Two reviewers (K.L. and O.R.) extracted the following data from included studies: (1) absence or presence of CAC in patients with COVID-19, (2) severity of the CAC, (3) number of ICU admissions, mechanical ventilations, and deaths in patients with COVID-19 with 
coronary calcifications present on imaging, and (4) number of ICU admissions, mechanical ventilations, and deaths in patients with COVID-19 without coronary calcifications on imaging. The data were compiled in Excel. Extracted data were crosschecked by both investigators (K.L. and O.R.) with the original sources.

\subsection{Risk of Bias Assessment}

Newcastle-Ottawa scale for cohort studies was applied to each included study in the analysis [4]. A composite score between 0 and 9 was calculated based on three categories. Arbitrary values were determined for studies' risk of bias: high risk 0-3; moderate risk 4-6; and low risk 7-9. A modified scale was used to calculate the score for Dillinger et al. (2020).

\subsection{Statistical Analysis}

Presence of CAC was compared with the absence of CAC based on the interests of outcome. The CAC data were further divided into absent, mild, moderate, or severe CAC in certain studies if it was reported. Absent and mild CAC were determined to be the "low CAC" group, and moderate and severe were stratified into the "high CAC" group. One study utilized the population's median CAC [5]. This median cutoff determined the "low CAC" and "high CAC" group. In Fazarri et al. (2021), CAC 0-299 was considered as "low CAC" group and above 300 was considered "high CAC" group.

Statistical analysis was performed on Microsoft Excel and PyMeta [6]. A random effects model was applied to the analysis. Presence of CAC and absence of CAC were recorded as well as the associated number of ICU admissions, mechanical ventilations, and deaths. The CAC severity was also recorded in respect to the interest of outcomes. Relative risk ratio and standard error were calculated for each outcome of interest. Inter-quartile ranges were calculated based on 95th percentile range from the aggregate data. Forest plots were used to visualize the analyses. Funnel plot was not applied due to the low number of studies in each outcome. Heterogeneity was assessed based on Cochrane Q score and $I^{2}$ index. Cochrane Q $p$-value was calculated based on chi-squared test. Degrees of heterogeneity were based on $I^{2}$ indices of $0-25 \%, 26-50 \%, 51-75 \%$, and $76-100 \%$, representing very low, low, moderate, and high degrees, respectively.

Based on available data of the original studies, two sets of analysis were performed. Effects of the presence of CAC and absence of CAC were measured. It was further investigated whether or not there was a statistical difference in the outcome based on the severity of the CAC.

\section{Results}

\subsection{Study Characteristics}

A total of eight studies were included in the analysis. Among the included, there were six retrospective cohort studies, one prospective cohort study, and one cross-sectional study. Analysis of these studies involved a total of 4542 individuals. Two studies were in the United States, five in Europe, and one in China. The studies did not have a consensus on method of CAC scoring and the cutoff for severity classification. V-CACS and Agatston scores were utilized in four and four studies, respectively. All studies had a Newcastle-Ottawa scale score between 8 and 9. A modified scale was used to evaluate Dillinger et al. 2020. Table 1 provides summary of the study characteristics, while Table 2 provides raw data from original sources.

\subsection{Death}

A total of five studies reported on death rates in patients with COVID-19 with concurrent reported CAC severity in total of 3769 patients. In the pooled analysis, there was an increased risk of mortality with higher CAC score compared with low CAC score (Figure 2A, RR, 2.74; 95\% CI, 1.94-3.86; $p<0.00001$ ). Further analysis was performed based on the death rates between patients with absent CAC and present CAC in a total of six studies. Luo et al. (2021) was excluded in the latter analysis due to lack of data in 
patients with absent CAC. There was evidence that CAC increased mortality compared with patients without CAC (Figure 2B, RR, 2.24; 95\% CI, 1.41-3.56; $p<0.001$ ).

Table 1. Summary of study characteristics.

\begin{tabular}{|c|c|c|c|c|c|}
\hline Study & Type of Study & Region & CAC Scoring & Events Reported & $\begin{array}{c}\text { Newcastle-Ottawa } \\
\text { Scale }\end{array}$ \\
\hline Luo et al. 2021 & $\begin{array}{l}\text { Retrospective } \\
\text { Cohort }\end{array}$ & China & V-CACS & $\begin{array}{c}\text { Death } \\
\text { Mechanical Ventilation } \\
\text { ICU Admission }\end{array}$ & 9 \\
\hline Gupta et al. 2021 & $\begin{array}{l}\text { Retrospective } \\
\text { Cohort }\end{array}$ & United States & V-CACS & $\begin{array}{c}\text { Death } \\
\text { Mechanical Ventilation } \\
\text { ICU Admission } \\
\text { Death }\end{array}$ & 9 \\
\hline Mousseaux et al. 2021 & Prospective Cohort & France & V-CACS & $\begin{array}{l}\text { Mechanical Ventilation } \\
\text { ICU Admission }\end{array}$ & 8 \\
\hline Fazzari et al. 2021 & $\begin{array}{l}\text { Retrospective } \\
\text { Cohort }\end{array}$ & Italy & Agatston & $\begin{array}{c}\text { Death } \\
\text { Mechanical Ventilation } \\
\text { ICU Admission }\end{array}$ & 9 \\
\hline Gianni et al. 2021 & $\begin{array}{l}\text { Retrospective } \\
\text { Cohort }\end{array}$ & Italy & Agatston & $\begin{array}{c}\text { Death } \\
\text { Mechanical Ventilation }\end{array}$ & 8 \\
\hline Dillinger et al. 2020 * & Cross-sectional & France & Agatston & $\begin{array}{c}\text { Death } \\
\text { Mechanical Ventilation }\end{array}$ & 8 \\
\hline Slipczuk et al. 2021 & $\begin{array}{l}\text { Retrospective } \\
\text { Cohort }\end{array}$ & United States & V-CACS & Death & 9 \\
\hline Zimmermann et al. 2021 & $\begin{array}{l}\text { Retrospective } \\
\text { Cohort }\end{array}$ & Germany & Agatston & $\begin{array}{c}\text { Death } \\
\text { ICU Admission }\end{array}$ & 8 \\
\hline
\end{tabular}

* Required modified Newcastle-Ottawa scale due to its study type.

Table 2. Individualized data of each study.

\begin{tabular}{|c|c|c|c|c|c|}
\hline Study & CAC Severity & Total Patients (N) & Death & $\begin{array}{c}\text { ICU } \\
\text { Admission }\end{array}$ & $\begin{array}{l}\text { Mechanical } \\
\text { Ventilation }\end{array}$ \\
\hline \multirow{2}{*}{ Luo et al. 2021} & High CAC & 177 & 27 & 37 & 23 \\
\hline & Low CAC & 1890 & 52 & 91 & 73 \\
\hline \multirow{4}{*}{ Gupta et al. 2021} & Absent & 51 & 8 & - & 13 \\
\hline & Mild & 42 & 15 & - & 15 \\
\hline & Moderate & 23 & 8 & - & 10 \\
\hline & Severe & 42 & 19 & - & 12 \\
\hline \multirow{4}{*}{ Mousseaux et al. 2021} & Absent & 64 & 7 & 21 & 17 \\
\hline & Mild & 42 & 11 & 17 & 8 \\
\hline & Moderate & 26 & 9 & 8 & 4 \\
\hline & Heavy & 37 & 17 & 7 & 7 \\
\hline \multirow{4}{*}{ Fazzari et al. 2021} & CAC 0 & 138 & 15 & 31 & 28 \\
\hline & CAC 1-299 & 94 & 22 & 27 & 25 \\
\hline & CAC 300-999 & 34 & 12 & 4 & 4 \\
\hline & $\mathrm{CAC} \geq 1000$ & 16 & 8 & 3 & 3 \\
\hline \multirow{2}{*}{ Gianni et al. 2021} & $\mathrm{CAC} \leq 335.48$ & 868 & 125 & - & 136 \\
\hline & CAC $>335.48$ & 225 & 86 & - & 19 \\
\hline \multirow{2}{*}{ Dillinger et al. 2020} & $\mathrm{CAC}=0$ & 103 & 2 & - & 10 \\
\hline & $C A C \geq 1$ & 106 & 7 & - & 20 \\
\hline \multirow{2}{*}{ Slipczuk et al. 2021} & $\mathrm{CAC}=0$ & 147 & 50 & - & - \\
\hline & $\mathrm{CAC} \geq 1$ & 308 & 131 & - & - \\
\hline \multirow{2}{*}{ Zimmermann et al. 2021} & $\mathrm{CAC}=0$ & 40 & 2 & 11 & - \\
\hline & $C A C \geq 1$ & 69 & 9 & 37 & - \\
\hline Total & - & 4542 & 642 & 294 & 427 \\
\hline
\end{tabular}




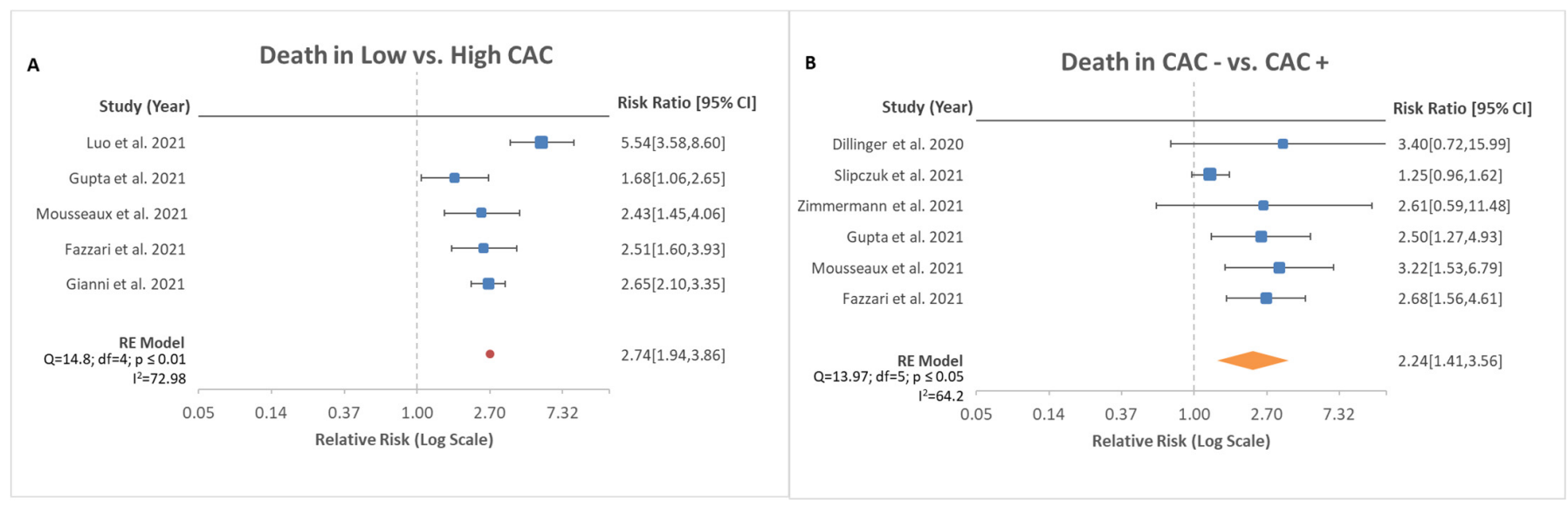

Figure 2. Risk ratio of death based on stratification of CAC scores. (A) depicts mortality in low CAC vs. high CAC with total of five studies analyzed with $95 \%$ confidence interval. Test for overall effect: $Z=5.71, p<0.00001$. (B) depicts mortality in absence of CAC vs. the presence of CAC with total of six studies analyzed with $95 \%$ confidence interval. Test for overall effect: $Z=3.40, p<0.001$.

\subsection{Mechanical Ventilation}

Mechanical ventilation event rates and severity of CAC were reported in five studies with a reported total of 397 patients out of 3769 patients. Based on the data, no difference was noted between patients with low CAC score and high CAC score in the events of mechanical ventilation (Figure 3A, RR, 1; 95\% CI, 0.48-2.09; $p=0.999$ ). Further analysis was conducted in four studies for patients with absent $C A C$ and present $C A C$ regarding mechanical ventilation rates. No difference was noted between those two groups as well (Figure 3B, RR, 1.38; 95\% CI, 0.97-1.97; $p=0.475$ ).

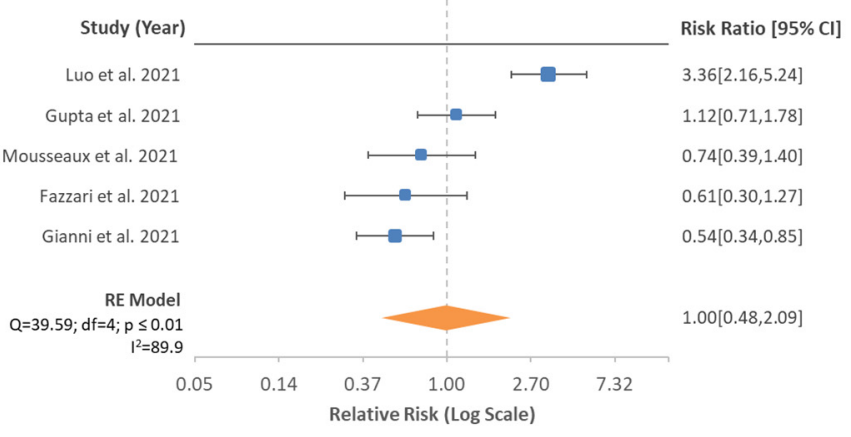

B

Mechanical Ventilation in CAC - vs. CAC +

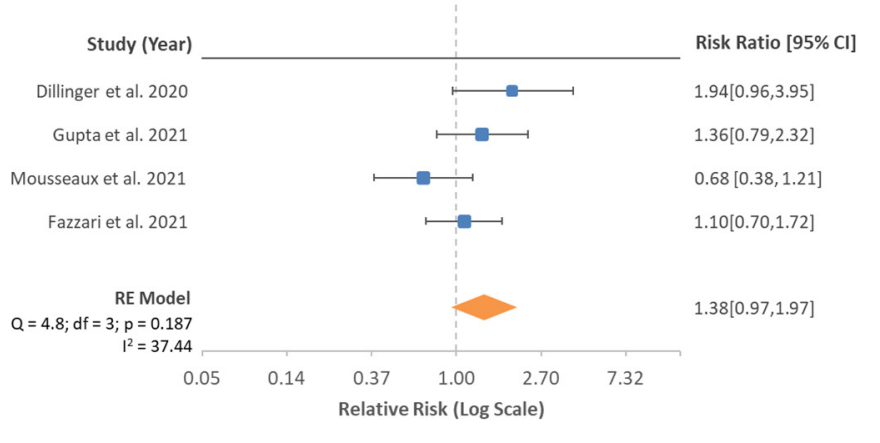

Figure 3. Risk ratio of mechanical ventilation based on stratification of CAC scores. (A) depicts risk in low CAC vs. high CAC with total of five studies analyzed with $95 \%$ confidence interval. Test for overall effect: $Z=0.00, p=0.99$. Test for overall effect: $Z=5.71, p<0.00001$. (B) depicts risk in absence of CAC vs. the presence of CAC with total of four studies analyzed with $95 \%$ confidence interval. Test for overall effect: $Z=0.72, p=0.48$.

\subsection{ICU Admission}

Both ICU admission rates and severity of CAC were reported in a total of three studies in a total of 2518 patients. Among the high CAC score group and low CAC score group, there was no significant difference noted (Figure 4A, RR, 1.2; 95\% CI, 0.27-5.33; $p=0.815$ ). Additional investigation was performed to observe whether rates differed in the presence of CAC and absence of CAC. However, no difference was found between patients with CAC and without CAC (Figure 4B, RR, 1.2; CI 0.80-1.82; $p=0.379$ ). 


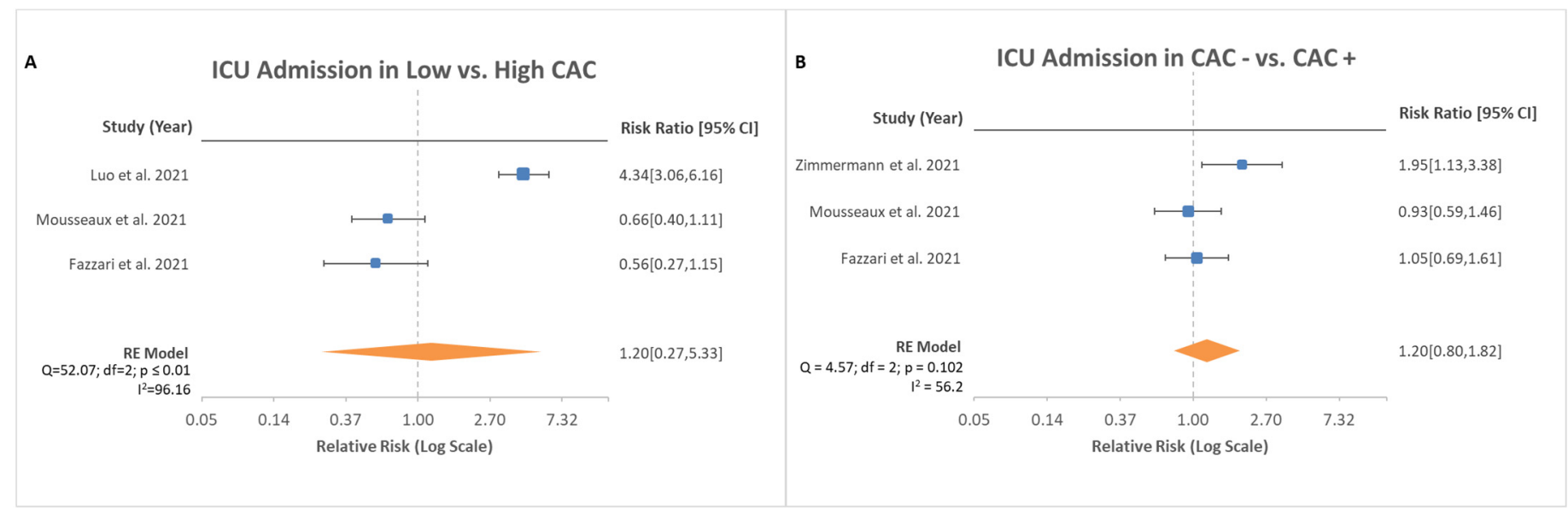

Figure 4. Risk ratio of ICU admission based on stratification of CAC scores. (A) depicts risk in low CAC vs. high CAC with total of three studies analyzed with $95 \%$ confidence interval. Test for overall effect: $Z=0.23, p=0.82$. (B) depicts risk in absence of CAC vs. the presence of CAC with total of three studies analyzed with $95 \%$ confidence interval. Test for overall effect: $Z=0.88, p=0.38$.

\section{Discussion}

CAC scoring can be defined by multiple methods [1]: Agatston scoring, volume score, mass score, and visualization score (V-CACS). The clinical application of CAC scoring allows delineation and risk stratification of patients with increased atherosclerotic risk $[1,7]$. CAC score can be obtained by a non-contrast computed tomography of the chest, which may be obtained at the time of COVID-19 diagnosis [8]. Although standardized cutoff values for CAC have previously been studied $[1,7]$, the actual utilized scoring and cutoffs for coronary studies seem user- and institution-dependent. Given the variability in the study methods, this analysis aimed to establish a systematic approach to comparison of CAC scores to synthesize and aggregate data. Few studies utilized V-CACS to separate the patients into absent, mild, moderate, and severe categories $[9,10]$. Other studies reported scores in Agatston format [5,11-14]. One study reported as "high CAC" and "low CAC" groups [15]. Based on the provided data, the reviewers classified those data into low CAC and high CAC group. This separation was based on the authors' opinion, so it may be subjected to observer bias. Objective data on the presence or absence of CAC were analyzed to minimize the risk of observer bias. These two parameters were used to assess risk of three clinical outcomes: death, mechanical ventilation, and ICU admission.

A history of coronary atherosclerotic disease (CAD) is known to be associated with a 10\% increased mortality risk in hospitalized patients with COVID-19 [16]. Other studies have reported similar findings. Additionally, COVID-19 has been associated with various cardiovascular complications $[17,18]$. Hyperinflammation, cytokine storm, lymphohistiocytosis, coronary microvascular thrombosis, and endotheliitis have been proposed to be possible mechanisms of acute myocardial injury in COVID-19 [19]. Slipczuk et al. (2021) measured the epicardial adipose tissue (EAT) and deemed it to be an independent risk factor for mortality in patients with COVID-19. Given the increased oxygen demand as well as cardiovascular strain and stress, patients with a history of CAD are at increased risk for worse clinical outcomes compared with their healthy counterparts. A single-center cohort study showed that there was a lower prevalence of myocardial injury if CAC was absent in patients with COVID-19 [20]. Absence of CAC had a high negative predictive value for major adverse cardiac events in patients hospitalized with COVID-19 even in the presence of other cardiac risk factors [21]. Based on the analysis, the presence of CAC alone increased the mortality rate for hospitalized patients with COVID-19 (Figure 2B). It may be safe to presume that patients with no known history of CAD may benefit from CAC scoring as a prognostic indicator for death during hospitalization. 
COVID-19 is a primary respiratory disorder that can lead to acute respiratory distress syndrome (ARDS), which for many patients may require mechanical ventilation [22]. ARDS is defined by noncardiogenic pulmonary edema that can lead to life threatening hypoxia from a lack of proper oxygen exchange within the lung parenchyma [23]. The therapy for ARDS in COVID-19 is multidisciplinary, but the mainstay for critically ill patients is low tidal volume mechanical ventilation [23]. The risk of being mechanically ventilated is based on a multitude of factors such as age, obesity, cardiovascular disease, and socioeconomic background [24]. In a single-center cohort study of 5279 patients, the strongest risk factor for development to severe illness and possible intubation, in addition to age, was heart failure, with an odds ratio of 1.9 [24]. This analysis looked to assess whether CAC was a possible risk factor for intubation and mechanical ventilation. Of the studies reviewed, Luo et al. (2021) noted an increased risk for mechanical ventilation with high CAC scores; however, the aggregate data were not consistent with this finding. All other studies that were reviewed found a lack of significant elevation in risk for mechanical ventilation related to CAC levels. These data suggest that CAC presence and severity is not an independent risk factor for mechanical ventilation in hospitalized patients with COVID-19.

Hospitalized patients with COVID-19 are at increased risk for multi-organ systemic disease. A study of 138 patients who developed critical illness found the median time from admission to critical care service to be 2.5 days after onset of symptoms [25]. This rapid deterioration can be attributed to the severe pulmonary insult from the infection, but many of these patients have other non-pulmonary complications that lead to ICU admission. The complications most notably found during these admissions include acute kidney injury, encephalopathy, thrombosis, and cardiac injury [24]. Cardiac complications have ranged from cardiomyopathy and arrythmia to myocardial infarction and cardiac arrest $[26,27]$. One single-center cohort found a 33 percent occurrence of cardiomyopathy in critically ill patients with COVID-19 [28]. This cardiomyopathy is primarily thought to be either related to the hypercoagulable state from increased inflammation leading to coronary thrombosis and ischemic heart disease or direct cardiac myocyte injury from the viral pathogen [29]. However, the contribution of each of these complications to major adverse cardiovascular outcomes has not been fully determined. In a study examining 700 critically ill patients with COVID-19 with arrhythmias, nine patients developed cardiac arrest, all of whom were in the ICU. The development of cardiac arrest was associated with acute in-hospital mortality [30]. With a short median time from admission to an ICU transfer, as well as the known cardiovascular complications that follow, early prognosis via CAC scoring may benefit to risk-stratify patients. As seen in Figure $3 \mathrm{~A}$, there was no significant difference noted between high and low CAC scores for ICU admission risk. There was also no significant difference noted in ICU admission risk whether any CAC was found. Given these findings, the risk of being admitted to an ICU for hospitalized patients with COVID-19 appears to be multifactorial in nature but independent of CAC scoring.

\section{Limitations of the Study}

This analysis reviewed eight studies on CAC and COVID-19 hospitalization but was not without its limitations. One such limitation was that in the collecting of the individual study data, the scoring of CAC via V-CACS is dependent on the operator who reviewed the CT images, therefore leading to observer bias. However, the studies minimized such bias by employing two independent reviewers. Even in studies with Agatston scores, the cutoff scores varied depending on the study. Additionally, there was no consensus on method of CAC scoring. However, the ordinal method of CAC scoring correlated well with the Agatston score in terms of predicting cardiovascular disease [31-33]. As such, the analysis between the prognosis difference of V-CACS and ordinal scoring was not pursued in this study. Nonetheless, it may be a topic of interest for future research in the setting of COVID-19. Furthermore, although eight studies were analyzed, not every study included data on ICU admission or risk of mechanical ventilation. 


\title{
5. Conclusions
}

This meta-analysis strictly examined the outcomes of interest in death, mechanical ventilation, and ICU admission while comparing the CAC scores in patients with COVID-19. The compiled data show that CAC was associated with mortality increase by approximately 2 folds. However, the exact mechanism of why CAC increases mortality rate is uncertain. It may be due to myocarditis, type 1 myocardial infarction, type 2 myocardial infarction, or other causes such as increased risk of cardiac arrest. Coronary atherosclerosis is known to be a significant risk factor for poor outcomes in COVID-19 hospitalizations. Patients with no known history of CAD can be non-invasively assessed for possible coronary atherosclerosis via CAC scoring. CAC scoring may not correlate directly with risk of mechanical ventilation or ICU admission in this patient population. Given these findings, CAC scoring can aid in stratifying patients, thus allowing earlier interventions in rapidly developing illnesses.

\begin{abstract}
Author Contributions: K.K.L. had full access to all of the data in the study and takes responsibility for the integrity of the data and the accuracy of the data analysis, including and especially any statistically significant values. The contribution of each author is as follows: Conceptualization, K.K.L., O.R., A.S. and D.H.; methodology, K.K.L., O.R., C.K.L., A.S. and D.H.; software, K.K.L. and C.K.L.; validation, K.K.L., O.R. and C.K.L.; formal analysis, K.K.L. and C.K.L.; investigation, K.K.L., O.R. and A.S.; resources, K.K.L., O.R., C.K.L., A.S. and D.H.; data curation, K.K.L. and C.K.L.; writing-original draft preparation, K.K.L., O.R., C.K.L., A.S. and D.H.; writing-review and editing, K.K.L., O.R., C.K.L., A.S. and D.H.; visualization, K.K.L.; supervision, A.S. and D.H.; project administration, K.K.L., A.S. and D.H.; funding acquisition, none. All authors have read and agreed to the published version of the manuscript.
\end{abstract}

Funding: This research received no external funding.

Institutional Review Board Statement: Not applicable.

Informed Consent Statement: Not applicable.

Data Availability Statement: Not applicable.

Conflicts of Interest: The authors declare no conflict of interest.

\section{References}

1. Arjmand, A. Coronary Artery Calcium Score: A Review. Iran. Red Crescent Med. J. 2013, 15, e16616. [CrossRef]

2. Ruzzenenti, G.; Maloberti, A.; Giani, V.; Biolcati, M.; Leidi, F.; Monticelli, M.; Grasso, E.; Cartella, I.; Palazzini, M.; Garatti, L.; et al. Covid and Cardiovascular Diseases: Direct and Indirect Damages and Future Perspective. High Blood Press. Cardiovasc. Prev. 2021, 28, 439-445. [CrossRef]

3. Page, M.J.; McKenzie, J.E.; Bossuyt, P.M.; Boutron, I.; Hoffmann, T.C.; Mulrow, C.D.; Shamseer, L.; Tetzlaff, J.M.; Akl, E.A.; Brennan, S.E.; et al. The PRISMA 2020 statement: An updated guideline for reporting systematic reviews. BMJ 2021, 372, n71. [CrossRef] [PubMed]

4. Ouzzani, M.; Hammady, H.; Fedorowicz, Z.; Elmagarmid, A. Rayyan-a web and mobile app for systematic reviews. Syst. Rev. 2016, 5, 210. [CrossRef]

5. Wells, G.; Shea, B.; O'Connell, D.; Peterson, J.; Welch, V.; Losos, M.; Tugwell, P. The Newcastle-Ottawa Scale (NOS) for Assessing the Quality of Nonrandomised Studies in Meta-Analyses. 2000. Available online: http://www3.med.unipmn.it/dispense_ebm/ 2009-2010/Corso\%20Perfezionamento\%20EBM_Faggiano/NOS_oxford.pdf (accessed on 4 December 2021).

6. Giannini, F.; Toselli, M.; Palmisano, A.; Cereda, A.; Vignale, D.; Leone, R.; Nicoletti, V.; Gnasso, C.; Monello, A.; Manfrini, M.; et al. Coronary and total thoracic calcium scores predict mortality and provides pathophysiologic insights in COVID-19 patients. J. Cardiovasc. Comput. Tomogr. 2021, 15, 421-430. [CrossRef]

7. Hongyong, D. PythonMeta. Available online: http:/ / www.pymeta.com (accessed on 4 December 2021).

8. Neves, P.O.; Andrade, J.; Monção, H. Coronary artery calcium score: Current status. Radiol. Bras. 2017, 50, 182-189. [CrossRef] [PubMed]

9. Jalaber, C.; Lapotre, T.; Morcet-Delattre, T.; Ribet, F.; Jouneau, S.; Lederlin, M. Chest CT in COVID-19 pneumonia: A review of current knowledge. Diagn. Interv. Imaging 2020, 101, 431-437. [CrossRef]

10. Gupta, Y.S.; Finkelstein, M.; Manna, S.; Toussie, D.; Bernheim, A.; Little, B.P.; Concepcion, J.; Maron, S.Z.; Jacobi, A.; Chung, M.; et al. Coronary artery calcification in COVID-19 patients: An imaging biomarker for adverse clinical outcomes. Clin. Imaging 2021, 77, 1-8. [CrossRef] [PubMed] 
11. Mousseaux, E.; Fayol, A.; Danchin, N.; Soulat, G.; Charpentier, E.; Livrozet, M.; Carves, J.-B.; Tea, V.; Salem, F.B.; Chamandi, C.; et al. Association between coronary artery calcifications and 6-month mortality in hospitalized patients with COVID-19. Diagn. Interv. Imaging 2021, 102, 717-725. [CrossRef] [PubMed]

12. Fazzari, F.; Cozzi, O.; Maurina, M.; Donghi, V.; Indolfi, E.; Curzi, M.; Leone, P.P.; Cannata, F.; Stefanini, G.G.; Chiti, A.; et al. In-hospital prognostic role of coronary atherosclerotic burden in COVID-19 patients. J. Cardiovasc. Med. 2021, $22,818-827$. [CrossRef] [PubMed]

13. Dillinger, J.G.; Benmessaoud, F.A.; Pezel, T.; Voicu, S.; Sideris, G.; Chergui, N.; Hamzi, L.; Chauvin, A.; Leroy, P.; Gautier, J.F.; et al. Coronary Artery Calcification and Complications in Patients With COVID-19. JACC Cardiovasc. Imaging 2020, 13, 2468-2470. [CrossRef]

14. Slipczuk, L.; Castagna, F.; Schonberger, A.; Novogrodsky, E.; Sekerak, R.; Dey, D.; Jorde, U.P.; Levsky, J.M.; Garcia, M.J. Coronary artery calcification and epicardial adipose tissue as independent predictors of mortality in COVID-19. Int. J. Cardiovasc. Imaging 2021, 37, 3093-3100. [CrossRef]

15. Zimmermann, G.S.; Fingerle, A.A.; Müller-Leisse, C.; Gassert, F.; von Schacky, C.E.; Ibrahim, T.; Laugwitz, K.-L.; Geisler, F.; Spinner, C.; Haller, B.; et al. Coronary calcium scoring assessed on native screening chest CT imaging as predictor for outcome in COVID-19: An analysis of a hospitalized German cohort. PLoS ONE 2020, 15, e0244707. [CrossRef]

16. Luo, S.; Qiu, X.M.; Zeng, X.J.; Zhang, D.Y.; Wan, B.; Li, X.; Tian, R.H.; Wang, J.T.; Wang, M.Y.; Zhu, J.; et al. Coronary artery calcification and risk of mortality and adverse outcomes in patients with COVID-19: A Chinese multicenter retrospective cohort study. Chin. J. Acad. Radiol. 2021. [CrossRef]

17. Madjid, M.; Safavi-Naeini, P.; Solomon, S.D.; Vardeny, O. Potential Effects of Coronaviruses on the Cardiovascular System. JAMA Cardiol. 2020, 5, 831. [CrossRef] [PubMed]

18. Basu-Ray, I.; Almaddah, N.K.; Adeboye, A.; Soos, M.P. Cardiac Manifestations Of Coronavirus (COVID-19). Treasure Island, FL. Available online: https:/ / www.ncbi.nlm.nih.gov/books/NBK556152/ (accessed on 4 December 2020).

19. Long, B.; Brady, W.J.; Koyfman, A.; Gottlieb, M. Cardiovascular complications in COVID-19. Am. J. Emerg. Med. 2020, 38, 1504-1507. [CrossRef]

20. Bavishi, C.; Bonow, R.O.; Trivedi, V.; Abbott, J.D.; Messerli, F.H.; Bhatt, D.L. Special Article-Acute myocardial injury in patients hospitalized with COVID-19 infection: A review. Prog. Cardiovasc. Dis. 2020, 63, 682-689. [CrossRef]

21. Ferrante, G.; Fazzari, F.; Cozzi, O.; Maurina, M.; Bragato, R.; D’Orazio, F.; Torrisi, C.; Lanza, E.; Indolfi, E.; Donghi, V.; et al Risk factors for myocardial injury and death in patients with COVID-19: Insights from a cohort study with chest computed tomography. Cardiovasc. Res. 2020, 116, 2239-2246. [CrossRef] [PubMed]

22. Luchian, M.-L.; Lochy, S.; Motoc, A.; Belsack, D.; Magne, J.; Roosens, B.; de Mey, J.; Tanaka, K.; Scheirlynck, E.; Boeckstaens, S.; et al. Prognostic Value of Coronary Artery Calcium Score in Hospitalized COVID-19 Patients. Front. Cardiovasc. Med. 2021, 8, 698. [CrossRef] [PubMed]

23. Bai, C.; Chotirmall, S.H.; Rello, J.; Alba, G.A.; Ginns, L.C.; Krishnan, J.A.; Rogers, R.; Bendstrup, E.; Burgel, P.-R.; Chalmers, J.D.; et al Updated guidance on the management of COVID-19: From an American Thoracic Society/European Respiratory Society coordinated International Task Force (29 July 2020). Eur. Respir. Rev. 2020, 29, 200287. [CrossRef] [PubMed]

24. Botta, M.; Tsonas, A.M.; Pillay, J.; Boers, L.S.; Algera, A.G.; Bos, L.D.J.; Dongelmans, D.A.; Hollmann, M.W.; Horn, J.; Vlaar A.P.J.; et al. Ventilation management and clinical outcomes in invasively ventilated patients with COVID-19 (PRoVENT-COVID): A national, multicentre, observational cohort study. Lancet Respir. Med. 2021, 9, 139-148. [CrossRef]

25. Petrilli, C.M.; Jones, S.A.; Yang, J.; Rajagopalan, H.; O’Donnell, L.; Chernyak, Y.; Tobin, K.A.; Cerfolio, R.J.; Francois, F.; Horwitz, L.I. Factors associated with hospital admission and critical illness among 5279 people with coronavirus disease 2019 in New York City: Prospective cohort study. BMJ 2020, 369, m1966. [CrossRef]

26. Wang, D.; Hu, B.; Hu, C.; Zhu, F.; Liu, X.; Zhang, J.; Wang, B.; Xiang, H.; Cheng, Z.; Xiong, Y.; et al. Clinical Characteristics of 138 Hospitalized Patients With 2019 Novel Coronavirus-Infected Pneumonia in Wuhan, China. JAMA 2020, 323, 1061. [CrossRef] [PubMed]

27. Gabarre, P.; Dumas, G.; Dupont, T.; Darmon, M.; Azoulay, E.; Zafrani, L. Acute kidney injury in critically ill patients with COVID-19. Intensive Care Med. 2020, 46, 1339-1348. [CrossRef] [PubMed]

28. Goyal, P.; Choi, J.J.; Pinheiro, L.C.; Schenck, E.J.; Chen, R.; Jabri, A.; Satlin, M.J.; Campion, T.R.; Nahid, M.; Ringel, J.B.; et al. Clinical Characteristics of Covid-19 in New York City. N. Engl. J. Med. 2020, 382, 2372-2374. [CrossRef]

29. Arentz, M.; Yim, E.; Klaff, L.; Lokhandwala, S.; Riedo, F.X.; Chong, M.; Lee, M. Characteristics and Outcomes of 21 Critically Ill Patients With COVID-19 in Washington State. JAMA 2020, 323, 1612-1614. [CrossRef]

30. Zheng, Y.-Y.; Ma, Y.-T.; Zhang, J.-Y.; Xie, X. COVID-19 and the cardiovascular system. Nat. Rev. Cardiol. 2020, 17, 259-260. [CrossRef]

31. Blair, K.J.; Allison, M.A.; Morgan, C.; Wassel, C.L.; Rifkin, D.E.; Wright, C.M.; Criqui, M.H.; Ix, J.H. Comparison of ordinal versus Agatston coronary calcification scoring for cardiovascular disease mortality in community-living individuals. Int. J. Cardiovasc. Imaging 2014, 30, 813-818. [CrossRef] 
32. Bhatt, S.P.; Kazerooni, E.A.; Newell, J.D.; Hokanson, J.E.; Budoff, M.J.; Dass, C.A.; Martinez, C.H.; Bodduluri, S.; Jacobson, F.L.; Yen, A.; et al. Visual Estimate of Coronary Artery Calcium Predicts Cardiovascular Disease in COPD. Chest 2018, 154, 579-587. [CrossRef]

33. Huang, Y.-L.; Wu, F.-Z.; Wang, Y.-C.; Ju, Y.-J.; Mar, G.-Y.; Chuo, C.-C.; Lin, H.-S.; Wu, M.-T. Reliable categorisation of visual scoring of coronary artery calcification on low-dose CT for lung cancer screening: Validation with the standard Agatston score. Eur. Radiol. 2013, 23, 1226-1233. [CrossRef] [PubMed] 